\title{
Farming in the Forest
}

\author{
Dirk Krausse
}

Published online: 3 April 2014

(c) Springer-Verlag Berlin Heidelberg 2014

On 11-15th July 2012, the Baden-Württemberg Landesamt für Denkmalpflege (State Office for the Protection of Monuments) held a symposium on "Farming in the Forest-Ecology and Economy of Fire in Prehistoric Agriculture" in Kloster Schöntal. The symposium was organised jointly with the Universities of Berlin and Bonn.

Since the 1990s experimental archaeology has been carried out near Schwäbisch Hall. Thanks to the generosity of the State Forest Administration, an area of about three hectares has been available for this project since 1998 for systematic experimental forest clearance and farming, and will be for at least 20 years. Research has already been going on in Wackershofen and Forchtenberg for nearly 20 years. Manfred Rösch is responsible for the Forchtenberg project. It is hard to believe, but true that Manfred Rösch carried out this partly "exotic" scientific work as a "civil servant" of the State of Baden-Württemberg.
Together with colleagues from various universities-of whom, first and foremost, Wolfram Schier should be mentioned here-he has gained astonishing new insights into prehistoric forest clearance by fire and farming. These results are not only of historical interest. The crop yields in the experiments are remarkably high, so that even modern farmers looking for alternative ways of pest and weed control could profit from the Forchtenberg experiments.

I would like to express our gratitude to the editors of the volume, Felix Bittmann, Renate Gerlach, Manfred Rösch and Wolfram Schier. On behalf of the Baden-Württemberg State Office for the Protection of Monuments I would also like to thank all the contributors, both the ones who attended the symposium in Schöntal and those who kindly contributed papers to the volume. The Schöntal symposium was funded by the Baden-Württemberg Ministry of Finance and Economics.
D. Krausse ( $\square)$

Landesamt für Denkmalpflege Baden-Württemberg,

Esslingen am Neckar, Germany

e-mail: dirk.krausse@rps.bwl.de 